\title{
Attitudes of medical students in Ireland towards psychiatry: comparison of students from 1994 and 2010
}

\author{
K. O'Connor, ${ }^{1,2}$ K. O'Loughlin, ${ }^{1,3}$ C. Somers, ${ }^{1,3}$ L. Wilson, ${ }^{1,4}$ D. Pillay, ${ }^{1,4}$ D. Brennan, ${ }^{2}$ \\ M. Clarke, ${ }^{2}$ A. Guerandel, ${ }^{1,3}$ P. Casey, ${ }^{1,4}$ K. Malone, ${ }^{1,3}$ A. Lane ${ }^{2}$
}

The Psychiatrist (2012), 36, 349-356, doi: 10.1192/pb.bp.111.037549

${ }^{1}$ University College Dublin, Dublin; ${ }^{2}$ St John of God Hospital, Stillorgan; ${ }^{3}$ St Vincent's Hospital, Dublin; ${ }^{4}$ Mater Hospital, Dublin, Ireland Correspondence: Karen O'Connor (karenoconnor2@hotmail.com) First received 20 Oct 2011, final revision 27 Mar 2012, accepted 11 Apr 2012

\begin{abstract}
Aims and method We assess and compare: (a) the attitudes of final-year medical students in 2010 to their 1994 counterparts; (b) the attitudes of third-year medical students with those of their final-year colleagues; (c) the impact of two different teaching modules on students' attitudes. All students completing the year 3 psychiatry preclinical module and the final-year clinical clerkship were asked to anonymously complete three well-validated attitudinal questionnaires on the first and final day of their module in psychiatry.
\end{abstract}

Results These data indicate that Irish medical students have a positive attitude to psychiatry even prior to the start of their clinical training in psychiatry. This attitude is significantly more positive now than it was in 1994. A positive attitudinal change was brought about only by the final-year psychiatric clerkship. Students who have completed a degree prior to medicine are less likely to express an interest in a career in psychiatry.

Clinical implications If we are to address the recruitment difficulties in psychiatry we need to look at innovative and specific ways of translating these positive attitudes into careers in psychiatry.

Declaration of interest None.
Medical student's attitudes towards psychiatry have an impact on their overall educational experience, the quality of care psychiatric patients receive from physicians in the future and also recruitment to the specialty. ${ }^{1,2}$ In a survey 16 years ago we found that the perception of psychiatry in an Irish university was positive prior to and immediately following an 8-week clinical clerkship and on completion of the programme there was an increase in the proportion of students who indicated that they might choose a career in psychiatry. ${ }^{3}$ A number of other studies have reported a positive change in attitude to psychiatry after a psychiatric clerkship, and others have failed to find any influence of a clerkship on students' attitudes (Box 1).

Recent changes in Ireland underlie the importance of re-evaluating medical student attitudes to psychiatry in a new era. The Irish healthcare system both at undergraduate and postgraduate level is going through a period of considerable flux and change. At undergraduate level in University College Dublin, class sizes have increased, there has been the introduction of undergraduate modularisation with a reduction in the duration of the final-year psychiatric clerkships and the introduction of thematic and small group teaching. At postgraduate level the implementation of the European Union (EU) working time directive has changed the way junior doctors work and possibly altered medical student access to clinical teams. Budgetary cuts in the healthcare system have reduced the staffing levels, increased the pressure on clinical teams, potentially altering the clerkship experience of psychiatry for students. In 2009 the College of Psychiatry of Ireland was formed. The College is an Irish-only body and emerged when three bodies

Box 1 Studies examining the effect of clerkship on medical student attitudes to psychiatry

Study

Attitudes

Araya et $a l^{4}$ (1992)

Positive

Sloan et al ${ }^{3}$ (1996)

Positive

Al-Ansari et $a l^{5}(2002)$

No change

Galka et $a l^{6}(2005)$

No change

Niedermier et $a l^{P}$ (2006)

Positive

Fischel et $\left.a\right|^{8}$ (2008)

No change

Sajid et $a l^{9}(2009)$

Positive

Xavier et $a l^{10}$ (2010)

Positive 
merged: The Irish College of Psychiatrists (a division of the Royal College of Psychiatrists UK), The Irish Psychiatric Association and The Irish Psychiatric Training Committee. According to some USA, British and Australian studies, the percentage of students choosing psychiatry as their future specialty has decreased considerably. ${ }^{11-13}$ A similar trend has been noted in Ireland, with less than $50 \%$ of first-year training posts in psychiatry in Ireland filled in July 2011. In the UK only $61 \%$ of core training posts in psychiatry for 2011 had been filled by the first round of specialty recruitment, despite the Royal College of Psychiatrists extending the application window by almost a month. ${ }^{14}$ All these factors have the potential to have an impact on medical student training and attitudes, warrant evaluation and may need to be considered in future training development if we are to recruit the best into the specialty.

In the UK, studies have consistently shown that only $3-4 \%$ of newly qualified doctors intend to pursue psychiatry as a career. ${ }^{15}$ These findings are in contrast to the findings of a study that looked at the career intentions of potential UK medical students, which found that $12.4 \%$ reported a definite intention of pursuing psychiatry. ${ }^{15}$ Although these studies are of different populations, authors have suggested that this might suggest a negative influence of undergraduate education on medical students' career aspirations to pursue psychiatry. ${ }^{16}$ Previous studies have reported decay in the interest of medical students in a career in psychiatry over the course of their medical school education. ${ }^{17}$ A number of studies have demonstrated a more positive attitude to psychiatry as a subject and as a potential career choice in preclinical rather than clinical medical students. ${ }^{15,18}$

\section{Aims}

In light of these findings and the earlier introduction of psychiatric teaching to the curriculum in University College Dublin, we felt the assessment and comparison of the preclinical and clinical-year students' attitudes to psychiatry and to a career in psychiatry in the same university could be instructive. Furthermore, little has been published on the capacity of a non-clinical teaching module to affect medical students' attitudes to psychiatry as a subject and as a potential career choice. Our aims were as follows.

(a) In light of significant changes at undergraduate and postgraduate education level in Ireland, to reassess and compare the attitudes of Irish final-year medical students to psychiatry in 2010 with their 1994 counterparts.

(b) Assess and compare the attitudes of third-year and final-year medical students in the same university to psychiatry and a career in psychiatry.

(c) Assess and compare the impact of two dierent teaching modules on the attitudes of medical students towards psychiatry and also towards a career in psychiatry.

\section{Method}

\section{Participants}

At University College Dublin, psychiatry is taught as part of an introductory multisubject module in the final preclinical year (year 3) and again as a final-year subject with half the class completing a clerkship in year 5 and the remaining half completing their psychiatry clerkship in their final year (year 6).

During the academic year of 2010/2011, all students completing the third-year psychiatry preclinical module and all students completing the final-year clinical clerkship were asked to anonymously complete three attitudinal questionnaires on the first day of teaching prior to receiving any tuition in psychiatry and again on the final day of their module in psychiatry immediately after their end of module multiple choice questionnaire (MCQ) examination.

In third year, a mandatory 9-week composite module of psychiatry, obstetrics and paediatrics is delivered. Each specialty gets equal teaching time. The psychiatric teaching in this module comprises a series of nine interactive lectures in psychiatry used in combination with e-learning materials and three small group workshops. At the end of the module, student's are assessed by objective structured clinical examination (OSCE) and an MCQ.

The final year mandatory 6-week clinical psychiatry clerkship consists of 6 weeks of clinical attachment where students are assigned to one of six centres where they are allocated to a multidisciplinary clinical team. Teaching is delivered thematically. Every morning there is a small group teaching session on the theme for the day, followed by team attachment when students are given specific theme-related tasks such as to assess a patient with a specific condition or elicit specific information from multidisciplinary team members. Each afternoon students have a lecture to summarise and reinforce what they have learnt. Under the supervision of the consultant and registrar the students are involved in the clinical assessment of in-patients, outpatients and day patients. Students are assessed by continuous assessment and case presentation (20\%), a reflective essay (20\%), an MCQ paper (20\%) and an OSCE (40\%).

In 1994 the mandatory 8-week psychiatry clerkship consisted of a 1-week introduction to psychiatry by means of didactic lectures followed by a 5-week unstructured clinical attachment. A sixth week was spent attached to a child and adolescent unit. In week 7 the students visited some subspecialty facilities such as the forensic unit and centres for learning disability. The final week consisted of revision with a tutor. The exam in 1994 consisted of a clinical casebased exam and a written paper.

\section{Questionnaires}

In order to facilitate a direct comparison with the study completed 16 years ago and also with previous studies, we used the following three questionnaires, which have been used in a number of published studies. All of these questionnaires have been validated as measures of the attitudes of medical students to psychiatry and have previously been shown to be sensitive to change. These questionnaires included: the Attitudes to Psychiatry (ATP30) scale, ${ }^{19}$ the Specific Attitude to Psychiatry (SATP) questionnaire ${ }^{20}$ and the Das \& Chandrasena questionnaire. ${ }^{1}$

Completion of all three questionnaires took approximately $20 \mathrm{~min}$. At the end of the module, students were asked to indicate their interest in psychiatry as a career and were encouraged to use the free-text section on the 
questionnaire to describe their subjective opinion of psychiatry. Data relating to gender, age and marital status were also compiled.

\section{The Attitudes to Psychiatry (ATP-30) scale}

The ATP-30 was validated on Canadian medical students and residents training in psychiatry. It was previously used in research of attitudes of both Kenyan ${ }^{7}$ and Arabian Gulf ${ }^{5}$ medical students. This is a 30 -item questionnaire designed to measure the influence of psychiatric training on attitudes to psychiatry held by undergraduate medical students. The ATP uses a five-point Likert-type scale: 1, strongly agree; 2, agree; 3, neutral opinion; 4, disagree; and 5, strongly disagree. A total attitudinal score was computed for each respondent. ${ }^{19}$

\section{The Specific Attitude to Psychiatry (SATP) questionnaire}

The SATP is a well-validated questionnaire and has previously been used in research of the attitudes of both British and Chilean medical undergraduates to psychiatry. ${ }^{20}$ It contains 18 individual items relating to psychiatrists, psychiatry and psychiatric treatment. Of the 18 items, 9 express positive views and 9 express negative views. Attitudes are measured on a four-point scale from one (strongly agree) to four (strongly disagree). There is no 'mixed feelings' category. Although there are no formal instructions from the authors regarding the calculation of a total score, it is possible to compute this using a method similar to that of the ATP-30.

\section{The Das \& Chandrasena questionnaire}

The Das \& Chandrasena questionnaire contains 26 items and was validated on Canadian medical students. ${ }^{1}$ It is an extended version of the questionnaire developed by Nielson $\&$ Eaton. ${ }^{2}$ Response is on a five-point Likert-type scale as for the ATP-30. It is not possible to calculate a total score using this questionnaire.

\section{Analysis}

Data were analysed using the Statistical Package for the Social Sciences (SPSS) version 17 on Windows. Paired $t$-tests were used in the analyses of pre- and post-module mean total scores. Wilcoxon signed rank test were used in the analyses of student responses to questionnaire items preand post-module and conventional $t$-tests to examine group differences. Pearson's correlation coefficient was used to examine correlations between continuous variables.

\section{Results}

In the final-year sample, 169 students of a total of 198 students completed at least one of the questionnaires, however only 147 students (88 females, 59 males) could be identified as completing both pre- and post-questionnaires and thus be included in the analysis (74\%). In the third-year sample, 150 students of a total of 196 students completed at least one of the questionnaires, however only 142 students (75 males, 67 females) could be identified as completing both pre- and post-questionnaires and thus be included in the analysis (72\%). For demographic details of the three groups see Table 1 .

In the 2010 final-year sample the pre-module mean score on the ATP-30 (logical neutral point: 90) was 112.5 $($ s.d. $=10)$ and this rose significantly $(P<0.001)$ to 118.83 (s.d. $=10.6)$ post-module (Table 2). Female students were statistically more likely to score higher on the pre-module ATP-30 than male students $(r=0.20, P<0.02)$. The SATP questionnaire has a neutral score of 45 . The pre-module mean SATP score of 52.9 (s.d. $=4.64$ ) increased significantly $(P<0.001)$ to 57.85 (s.d. $=4.30)$ at the end of the module.

Compared with the final-year students in 1994, finalyear students in 2010 were significantly more positive in their attitude to psychiatry both pre- and post-clerkship, as measured on the ATP-30 and on the SATP (Table 2). In 1994 the ATP-30 pre-clerkship mean was $98.4($ s.d. =3.5) and the

\begin{tabular}{|c|c|c|c|}
\hline & \multicolumn{3}{|c|}{$n(\%)$} \\
\hline & $\begin{array}{l}\text { Third year, } 2010 \\
\quad(n=142)\end{array}$ & $\begin{array}{l}\text { Final year, } 2010 \\
\qquad(n=147)^{\mathrm{a}}\end{array}$ & $\begin{array}{c}\text { Final year, } 1994 \\
\quad(n=110)\end{array}$ \\
\hline \multicolumn{4}{|l|}{ Gender } \\
\hline Male & $75(53)$ & $59(40)$ & $51(46)$ \\
\hline Female & $67(47)$ & $88(60)$ & $59(54)$ \\
\hline \multicolumn{4}{|c|}{ Marital status } \\
\hline Single & $139(98)$ & $142(97)$ & $105(95)$ \\
\hline Married & $2(2)$ & $2(1)$ & $5(5)$ \\
\hline \multicolumn{4}{|l|}{ Nationality } \\
\hline Irish & $101(71)$ & $106(72)$ & N/A \\
\hline Malaysian & $16(11)$ & $22(15)$ & N/A \\
\hline Canadian & $9(7)$ & $14(10)$ & N/A \\
\hline American & 7 (5) & $2(1)$ & N/A \\
\hline Other & $9(7)$ & $2(1)$ & N/A \\
\hline \multicolumn{4}{|c|}{ Medicine first degree? } \\
\hline Yes & $103(73)$ & $130(88)$ & N/A \\
\hline No & $39(27)$ & $17(12)$ & N/A \\
\hline
\end{tabular}

N/A, information not available.

a. One student did not disclose their nationality. 


\begin{tabular}{|c|c|c|c|c|}
\hline & Pre-clerkship, mean (s.d.) & Post-clerkship, mean (s.d.) & Paired $t$-test & $P$ \\
\hline \multicolumn{5}{|l|}{ Final year, 2010} \\
\hline \multicolumn{5}{|l|}{ ATP-30 questionnaire } \\
\hline Total $(n=147)$ & $112.5(10)$ & $118.8(10.6)$ & -5.39 & $<0.001$ \\
\hline Males $(n=59)$ & $110.5(10.6)$ & $116.9(10.9)$ & -3.24 & $<0.002$ \\
\hline Females $(n=88)$ & $113.9(9.3)$ & $120.0(10.2)$ & -4.35 & $<0.001$ \\
\hline \multicolumn{5}{|l|}{ SATP questionnaire } \\
\hline Total $(n=147)$ & $52.9(4.6)$ & $57.9(4.3)$ & -8.00 & $<0.001$ \\
\hline Males $(n=59)$ & $51.8(4.3)$ & $58.0(5.0)$ & -7.03 & $<0.001$ \\
\hline Females $(n=88)$ & $53.7(4.7)$ & $57.7(3.8)$ & -6.20 & $<0.001$ \\
\hline \multicolumn{5}{|l|}{ Third year, 2010} \\
\hline \multicolumn{5}{|l|}{ ATP-30 questionnaire } \\
\hline Total $(n=142)$ & $107.0(11.2)$ & $107.5(12.7)$ & -0.2 & NS \\
\hline Males $(n=75)$ & $106.4(11.2)$ & $107.2(12.8)$ & -0.4 & NS \\
\hline Females $(n=67)$ & $107.8(11)$ & $109.5(11)$ & -0.9 & NS \\
\hline \multicolumn{5}{|l|}{ SATP questionnaire } \\
\hline Total $(n=142)$ & $52.0(6.5)$ & $52.5(5.7)$ & -1.1 & NS \\
\hline Males $(n=75)$ & $53.0(5.6)$ & $54.5(6.0)$ & -0.8 & NS \\
\hline Females $(n=67)$ & $52.9(6.0)$ & $52.0(5.3)$ & 0.9 & NS \\
\hline \multicolumn{5}{|l|}{ Final year, 1994} \\
\hline \multicolumn{5}{|l|}{ ATP-30 questionnaire } \\
\hline Total $(n=98)$ & $98.4(3.5)$ & $107.3(2.3)$ & -22.13 & $<0.001$ \\
\hline Males $(n=45)$ & $99.0(3.4)$ & $107.1(2.5)$ & -17.12 & $<0.001$ \\
\hline Females $(n=53)$ & $97.9(3.6)$ & $107.1(2.5)$ & -14.42 & $<0.001$ \\
\hline \multicolumn{5}{|l|}{ SATP questionnaire } \\
\hline Total $(n=105)$ & $49.5(3.3)$ & $53.9(1.4)$ & -11.44 & $<0.001$ \\
\hline Males $(n=49)$ & $49.4(1.7)$ & $54.0(1.6)$ & -17.16 & $<0.001$ \\
\hline Females $(n=56)$ & $49.7(4.2)$ & $53.8(1.4)$ & -6.06 & $<0.001$ \\
\hline
\end{tabular}

SATP pre-clerkship mean was 49.5 (s.d. = 3.3). The difference between the 1994 sample and the 2010 sample was statistically significant for both pre-clerkship means (ATP30: $t=13.4, P<0.001$; SATP: $t=6.3, P<0.001)$. Post-clerkship in the 1994 sample the ATP-30 had a mean of 107.3 $($ s.d. $=2.3)$ and the SATP had a mean of 53.9 (s.d.=1.4). The difference between the two samples post-clerkship score was also statistically significant (ATP: $t=10.6$, $P<0.001$; SATP: $t=8.7835, P<0.001)$. In both studies there was a statistically significant rise in the ATP-30 and SATP post-clerkship means (Table 2).

In the 2010 third-year sample the pre-module mean score on the ATP-30 was lower than the 2010 final-year sample at 107 (s.d. = 11.2) but higher than the 1994 final-year sample. The post-module score was 107.5 (s.d. =12.7), this was not a statistically significant increase. The pre-module mean SATP score was also lower than the 2010 final-year sample at 52 (s.d. $=6.5$ ) but higher than the 1994 final-year sample. The SATP score rose, although not with significance, to 52.5 (s.d. =5.7). There was no relationship between gender and either of the post-module total scores on the ATP-30 or the SATP (Table 2).

\section{ATP-30}

Results of the Wilcoxon signed rank test for individual questionnaire items that showed significant change from pre- to post-module are displayed in Table 3. In 1994, postclerkship students were more likely to believe that 'Psychiatric training increases our understanding of medical and surgical patients' only. No other statistically significant changes occurred in items on the ATP-30 in the 1994 sample.

\section{Das \& Chandrasena questionnaire}

Table 4 describes the items that showed significant changes from pre- to post-module for the 2010 final-year and thirdyear students. In the 1994 sample, only one item on this questionnaire changed significantly after the clerkship, this was that 'Psychiatrists should, where necessary, continue to have the legal power to treat patients against their will'; the percentage of students who agreed with this statement rose from $3.6 \%$ to $40 \%$ post-clerkship. In the 2010 final-year sample, $78 \%$ of students agreed with this statement prior to their module and this rose to $81 \%$ after completion of the module.

\section{SATP}

In the 1994 study, statistically significant changes occurred in 3 of the 18 items. Although only one of these changes is replicated in the 2010 sample, four items did change significantly (Table 5). In the 1994 study, $58 \%$ of students prior to the clerkship agreed that psychiatrists 'are more concerned than other doctors to establish rapport with their patients': this rose to $85 \%$ post-clerkship. In $2010,95 \%$ of students agreed with this statement prior to the module and $96 \%$ agreed after. In the 1994 study, $57 \%$ of students prior to the clerkship agreed that 'Psychiatric skills are essential in general practice': this rose to $95 \%$ after the clerkship. In our study $93 \%$ agreed with this statement pre-module and $93 \%$ 


\begin{tabular}{|c|c|c|c|c|c|}
\hline \multirow[b]{2}{*}{ Item } & \multicolumn{2}{|c|}{ Pre-module, \% ( $n)$} & \multicolumn{2}{|c|}{ Post-module, \% (n) } & \multirow{2}{*}{$\begin{array}{c}\text { Wilcoxor } \\
Z\end{array}$} \\
\hline & Agree & Disagree & Agree & Disagree & \\
\hline $\begin{array}{l}\text { Final year }(n=147) \\
\text { 9. Psychiatric training increases our understanding of medical } \\
\text { and surgical patients } \\
\text { 10. The majority of students report that their psychiatric } \\
\text { undergraduate training has been valuable } \\
\text { 23. These days psychiatry is the most important part of the } \\
\text { curriculum } \\
\text { 25. In recent years psychiatric treatment has become quite } \\
\text { effective } \\
\text { 29. Psychiatric patients are often more interesting to work with } \\
\text { than other patients }\end{array}$ & $\begin{array}{l}79(116) \\
63(93) \\
10(15) \\
67(98) \\
55(81)\end{array}$ & $\begin{array}{c}9(13) \\
3(5) \\
70(104) \\
3(5) \\
8(12)\end{array}$ & $\begin{array}{l}86(127) \\
84(124) \\
18(26) \\
87(128) \\
76(112)\end{array}$ & $\begin{array}{c}7(10) \\
5(7) \\
60(88) \\
5(7) \\
8(12)\end{array}$ & $\begin{array}{l}3.77^{\star \star \star} \\
4.65^{\star \star \star} \\
2.20^{\star} \\
4.62^{\star \star *} \\
5.27^{\star \star *}\end{array}$ \\
\hline $\begin{array}{l}\text { Third year }(n=142) \\
\text { 23. These days psychiatry is the most important part of the } \\
\text { curriculum } \\
\text { 25. In recent years psychiatric treatment has become quite } \\
\text { effective }\end{array}$ & $\begin{array}{c}4(6) \\
54(77)\end{array}$ & $68(97)$ & $\begin{array}{l}20(28) \\
73(104)\end{array}$ & $46(65)$ & $2.0^{*}$ \\
\hline
\end{tabular}

${ }^{\star} P<0.05 ;{ }^{* \star} P<0.01 ;{ }^{* \star \star} P<0.001$.

\begin{tabular}{|c|c|c|c|c|c|}
\hline \multirow[b]{2}{*}{ Item } & \multicolumn{2}{|c|}{ Pre-module, \% (n) } & \multicolumn{2}{|c|}{ Post-module, \% (n) } & \multirow{2}{*}{$\begin{array}{c}\text { Wilcoxon } \\
\text { Z }\end{array}$} \\
\hline & Agree & Disagree & Agree & Disagree & \\
\hline \multicolumn{6}{|l|}{ Final year $(n=147)$} \\
\hline $\begin{array}{l}\text { 1. Psychiatry has advanced considerably in recent years in the } \\
\text { biological treatment and understanding of schizophrenia and } \\
\text { bipolar }\end{array}$ & $67(98)$ & $2(3)$ & $91(133)$ & $3(5)$ & $4.65^{\star * *}$ \\
\hline $\begin{array}{l}\text { 5. If someone in my family was very emotionally upset and the } \\
\text { situation didn't seem to be improving, I would recommend a } \\
\text { psychiatric consultation }\end{array}$ & $67(98)$ & $6(9)$ & $83(122)$ & $3(5)$ & $3.37 * * *$ \\
\hline $\begin{array}{l}\text { 6. Psychiatric consultations for medical and surgical patients are } \\
\text { only rarely helpful }\end{array}$ & $3(5)$ & $69(101)$ & $1(2)$ & $90(132)$ & $4.43^{* * *}$ \\
\hline 24. There is no place for ECT in modern medicine & $9(13)$ & $46(67)$ & $2(3)$ & $89(131)$ & $9.10^{\star * *}$ \\
\hline \multicolumn{6}{|l|}{ Third year $(n=142)$} \\
\hline 24. There is no place for ECT in modern medicine & $24(34)$ & $50(71)$ & $8(11)$ & $84(119)$ & $4.2^{* * *}$ \\
\hline
\end{tabular}

ECT, electroconvulsive therapy.

$\star \star \star P<0.001$

post-module. The final SATP item that reached statistical significance in the 1994 study and also in the 2010 study was that 'Too little time is devoted to psychiatry in the medical curriculum'. In 1994, prior to the clerkship 30\% of students agreed with this statement and $46 \%$ agreed post-clerkship. In the 2010 sample, $38.6 \%$ of students agreed with this statement prior and $50 \%$ after the module.

We found no correlation between the ATP-30 or SATP scores and the end of module exam results. No association was found between age and attitudes to psychiatry or interest in a career in psychiatry. No association was found between a family member working in mental health services and scores on the ATP-30 or SATP pre- or post-module. Students who expressed an interest in becoming a psychiatrist at the end of either of the modules were more likely to score higher on both the ATP-30 and the SATP (third year: $r=-0.55, P<0.001$; final year: $r=-0.44, P<0.001$ ).

In response to the question 'Would you like to be a psychiatrist?', prior to the module $18 \%(n=26)$ of final-year students and $22 \%(n=32)$ of third-year students stated they would and this increased to $33 \%(n=49)$ of final-year students and $32 \%(n=47)$ of the third-year students after. Students in the third year were no more likely than their final-year colleagues to express an interest in becoming a psychiatrist, however $14 \%$ of third-year students $(n=20)$ wrote in the free-text section that they were undecided and awaited the clinical attachment in the final year. Those students for whom medicine was not their first degree were less likely to report an interest in psychiatry as a career $(r=0.275, P<0.05)$. In response to a similar if less specific question in 1994 'Have you ever considered taking up psychiatry?', $45 \%$ of students stated that they had prior to the clerkship, whereas afterwards 57\% stated they had.

In the free-text section in the post-module questionnaire only $7 \%(n=10)$ of the final-year students expressed negative opinions about psychiatry, whereas only $3 \%(n=4)$ of third-year students expressed negative opinions about psychiatry. Examples of these negative attitudes included 


\begin{tabular}{|c|c|c|c|c|c|}
\hline \multirow[b]{2}{*}{ Item } & \multicolumn{2}{|c|}{ Pre-module, \% ( $n)$} & \multicolumn{2}{|c|}{ Post-module, \% (n) } & \multirow{2}{*}{$\begin{array}{l}\text { Wilcoxon } \\
\quad Z\end{array}$} \\
\hline & Agree & Disagree & Agree & Disagree & \\
\hline \multicolumn{6}{|l|}{ Final year $(n=147)$} \\
\hline 8. Psychiatric patients hardly ever get better & $33(49)$ & $67(98)$ & $5(7)$ & $95(140)$ & $5.50 * \star \star *$ \\
\hline $\begin{array}{l}\text { 10. Within medicine, psychiatry is one of the less important } \\
\text { specialties }\end{array}$ & $22(32)$ & $79(116)$ & $1(1)$ & $89(131)$ & $2.89 * * *$ \\
\hline $\begin{array}{l}\text { 14. Too little time is devoted to psychiatry in the medical } \\
\text { curriculum }\end{array}$ & $35(52)$ & $57(83)$ & $64(94)$ & $34(50)$ & $3.13^{* *}$ \\
\hline 18. Psychiatric patients, generally speaking are not easy to like & $32(47)$ & $62(91)$ & $9(13)$ & $87(128)$ & $4.95^{\star * *}$ \\
\hline \multicolumn{6}{|l|}{ Third year $(n=142)$} \\
\hline \multirow{2}{*}{$\begin{array}{l}\text { 8. Psychiatric patients hardly ever get better } \\
\text { 10. Within medicine, psychiatry is one of the less important } \\
\text { specialties }\end{array}$} & $35(50)$ & $65(92)$ & $11(15)$ & $87(124)$ & $4.30^{* * *}$ \\
\hline & $23(33)$ & $77(109)$ & $8(12)$ & $87(124)$ & $2.2^{\star *}$ \\
\hline
\end{tabular}

${ }^{\star \star} P<0.01 ;{ }^{* \star \star} P<0.001$

statements that psychiatry was 'too slow paced', 'too emotionally demanding' and 'just not for me'. No association was found between those students who expressed negative opinions of psychiatry and scores on the ATP-30 or the SATP. However, there was a trend for students who spontaneously expressed negative or critical attitudes to psychiatry to have poorer psychiatry examination results when compared with the remainder of the students $(t=-1.7, P=0.07)$. In $1994,34 \%$ of students expressed negative attitudes to psychiatry; views expressed at this time included statements that psychiatry was 'too vague', 'unscientific', 'depressing' and that it was associated with 'low job satisfaction'.

\section{Discussion}

\section{Limitations}

A particular methodological issue that must be addressed is that despite assurances otherwise, students may perceive that negative answers on the surveys, in particular prior to their clerkships, may result in less favourable treatment during their module. Thus inducing a bias towards an 'expected' group response. Anonymity was assured but students may not necessarily believe this to be the case, and so adjust their responses accordingly. We took several measures to reduce bias from fear of revealing negative attitudes, and to diminish any tendencies to give a socially favourable response. First, participation was optional; second, students were assured that their responses would not be analysed until the end of all of their psychiatry modules. Furthermore, we allowed a free-text response to allow students to express their opinion of psychiatry and to outline the reasons they would or would not consider a career in psychiatry. The responses in this free text were sufficiently disparate to assure us that they were expressing their genuine opinions.

\section{Main findings}

The attitudes of preclinical and clinical medical students in Ireland towards psychiatry are positive even prior to any teaching in psychiatry as evidenced by their scores on the
ATP-30 and SATP. These attitudes are more positive now than they were in 1994. Unlike the findings of other studies, prior to commencing the modules the final-year and thirdyear students did not differ significantly in their attitudes to psychiatry.

\section{Possible explanations for findings}

A number of factors may explain the more positive attitude to psychiatry seen in this final-year sample of Irish students compared with their 1994 counterparts. Some authors believe that the general opinion of psychiatry is gradually improving, together with its social image in general. ${ }^{21,22}$ Psychiatry is now being introduced at an earlier stage of the curriculum and all final-year students in the 2010 sample themselves completed the third-year composite module that included some psychiatry teaching. Authors have suggested that the overemphasis on acute hospital-based medicine during undergraduate training acts as a powerful disincentive for recruitment into primary care and the same may apply for psychiatry. ${ }^{23}$ Others feel that influences are less subtle, with direct negative effects on attitudes to psychiatry occurring during medical and surgical training. ${ }^{24}$ It would seem reasonable to propose that the preclinical teaching in psychiatry could have prevented the decay in attitude during the clinical years that has been described in other studies.

The post-module scores of the 2010 final-year sample are also higher than the 1994 sample. Although this may seem unsurprising in light of the higher pre-module scores, one could also say that the higher pre-module scores make a significant shift in attitude even more difficult to achieve. A factor that may be contributing to this finding is the new psychiatric curriculum, which although shorter is using newer teaching methods and is more inclusive of other medical specialties thereby increasing the relevance of psychiatry to medical training overall. Other studies have found that shorter but more interactive teaching methods are at least as, if not more, effective than traditional clerkships characterised by old-style didactic lectures. ${ }^{25}$

The third-year medical students who participated in a composite module that had psychiatry teaching as a component did not demonstrate a change - either positive 
or negative - in their attitude to psychiatry. This is in contrast with their final-year colleagues who after completion of their 6-week clinical attachment demonstrated significant improvements in their attitudes to psychiatry as a specialty and their interest in psychiatry as a career. This suggests that the clinical module, with its emphasis on patients and psychiatric team contact, has the greater capacity to change medical students' attitudes at least in the short term. So although the earlier introduction of psychiatry into the teaching curriculum of medical school may not itself alter attitudes to psychiatry, it may reinforce pre-existing positive attitudes and increase the likelihood that they will be maintained during and after the clinical years.

Students who have completed a degree prior to medicine were less likely in this study to express an interest in a career in psychiatry. Irish medical schools, on the basis of government recommendations in 2006, have been increasing the intake of graduate entry students to medicine. ${ }^{26}$ Psychiatry had expected, based on previous research, to benefit from this in that graduates might be more likely to consider a career in psychiatry. ${ }^{27,28}$ However, our study does not show this to be likely in Ireland. Nemetz \& Weiner found that those who chose psychiatry had majored more often in the humanities or social sciences rather than the natural sciences. ${ }^{28} \mathrm{~A}$ similar study in Canada found that those students expressing an interest in a career in psychiatry are more likely to have completed an undergraduate degree in the humanities than the biological sciences. ${ }^{29}$ However, entry requirements to Irish graduate medical school may prejudice entry in favour of a background in biological science as opposed to social science or the humanities. Results from our study suggest that graduate-entry medical students at University College Dublin $(n=56)$ are entering medicine with a bachelor degree in the natural sciences $(n=41,73 \%)$ rather than from the humanities/social sciences $(n=3,5 \%)$. This is an issue not only for Irish psychiatry but also psychiatry across Europe as graduate entry into medicine increases in prevalence. Of particular concern is the fact that some UK universities restrict entry to graduate medicine to graduates in the biological sciences. ${ }^{30}$

After completing the module we found a significant rise in the proportion of students who stated that they would like to be a psychiatrist. However, neither the apparent positive attitude to psychiatry nor the declared intention by medical students to follow a career in psychiatry appears to be translating into increased recruitment into the specialty. The transient nature of attitudinal changes has been well described. ${ }^{11}$ Perhaps stated career intentions in medical school, even in the final year, may not necessarily translate into an actual career choice post-internship. Mowbray \& Davies found that $65 \%$ of students who chose a career in psychiatry do so after graduation. ${ }^{31}$ It may be that students are attracted to the module they are completing at the time and as other specialties get more time in the medical school curriculum the interest ignited or fanned by the psychiatric clerkship wanes in the face of other medical experiences. It does seem that the more exposure students have (to either community or hospital medicine), the keener they become on careers in those areas. ${ }^{32} \mathrm{~A}$ development that may help to address this in Ireland is that in 2011 for the first time intern positions in psychiatry became available. Similar programmes in the UK have anecdotally been associated with positive recruitment outcomes.

\section{Implications}

Our data suggest that the past 16 years have seen a significant improvement in the attitudes of medical students to psychiatry, however this has not corresponded to increased recruitment into psychiatry. The challenge, which is not unique to Ireland, is how to reduce the dissonance between a positive attitude to psychiatry as a specialty, and the actual choice of psychiatry as a career. The findings of this study call for further investigation in Ireland regarding the factors influencing medical students that determine the ultimate choice of or rejection of psychiatry as a career.

\section{About the authors}

K. O'Connor is a Special Lecturer in the Department of Psychiatry, University College Dublin and a Senior Registrar at St John of God Hospital in Stillorgan. K. O'Loughlin is a Special Lecturer in the Department of Psychiatry, University College Dublin and a Senior Registrar at St Vincent's Hospital, Dublin. C. Somers is a Special Lecturer in the Department of Psychiatry, University College Dublin and a Senior Registrar at St Vincent's Hospital, Dublin. L. Wilson is a Special Lecturer in the Department of Psychiatry, University College Dublin and a Registrar at Mater Hospital, Dublin. D. Pillay is a Special Lecturer in the Department of Psychiatry, University College Dublin and a Registrar at Mater Hospital, Dublin. D. Brennan is a Librarian at St John of God Hospital, Stillorgan. M. Clarke is a Consultant Psychiatrist at St John of God Hospital, Stillorgan. A. Guerandel is a Consultant Psychiatrist in the Department of Psychiatry, University College Dublin and a Senior Clinical Lecturer at St Vincent's Hospital, Dublin. P. Casey is Professor of Psychiatry in the Department of Psychiatry, University College Dublin and Professor of Psychiatry at Mater Hospital, Dublin. K. Malone is Professor of Psychiatry in the Department of Psychiatry, University College Dublin and Professor of Psychiatry at St Vincent's Hospital, Dublin. A. Lane is a Consultant Psychiatrist at St John of God Hospital, Stillorgan.

\section{Acknowledgements}

We would like to acknowledge the considerable work of the group who published the 1996 paper: Dr Darina Sloan, Dr Stephen Browne, Dr Diane Meagher, Dr Conall Larkin, Professor Patricia Casey, Professor Noel Walsh and Professor Eadbhard O'Callaghan.

\section{References}

1 Das MP, Chandrasena RD. Medical students' attitudes towards psychiatry. J Med Educ 1982; 16: 31-8.

2 Nielson AC, Eaton J. Medical students attitude about psychiatry. Arch Gen Psychiatry 1981; 38: 1144-54

3 Sloan D, Browne S, Meagher D, Lane A, Larkin C, Casey P, et al. Attitudes toward psychiatry among Irish final year medical students. Eur Psychiatry 1996; 11: 407-11.

4 Araya RI, Jasresic E, Wilkinson G. Medical students' attitudes to psychiatry in Chile. J Med Educ 1992; 26: 153-6.

5 Al-Ansari A, Alsadadi A. Attitude of Arabian Gulf university medical students towards psychiatry. Educ Health 2002; 15: 180-8.

6 Galka SW, Perkins DV, Butler N, Griffith DA, Schmetzer AD, Avirrappattu G, et al. Medical students' attitudes toward mental 
disorders before and after a psychiatric rotation. Acad Psychiatry 2005: 29: 357-61.

7 Niedermier JA, Bornstein R, Brandemihl A. The junior medical student psychiatry clerkship: curriculum, attitudes, and test performance. Acad Psychiatry 2006; 30: 136-43.

8 Fischel T, Manna H, Krivoy A, Lewis M, Weizman A. Does a clerkship in Psychiatry contribute to changing medical students' attitudes towards psychiatry? Acad Psychiatry 2008; 32: 147-50.

9 Sajid A, Khan MM, Shakir M, Moazam-Zaman R, Ali A. The effect of clinical clerkship on students' attitudes toward psychiatry in Karachi, Pakistan. Acad Psychiatry 2009; 33: 212-4.

10 Xavier M, Almeida JC. Impact of clerkship in the attitudes toward psychiatry among Portuguese medical students. BMC Med Educ 2010; 10: 56

11 Brockington IF, Mumford DB. Recruitment into psychiatry. Br J Psychiatry 2002; 180: 307-12.

12 Balon R, Franchini G, Freeman P, Hassenfeld IN, Keshaven MS, Yoder E. Medical students' attitudes and views of psychiatry 15 years later. Acad Psychiatry 1999; 23: 30-6.

13 Malhi GS, Parker GB, Parker K, Kirkby KC, Boyce P, Yellowlees P, et al. Shrinking away from psychiatry? A survey of Australian medical students' interest in psychiatry. Aust N Z J Psychiatry 2002; 36: 416-23.

14 Jacques $\mathrm{H}$. A third of psychiatry core training posts are vacant after round one of specialty recruitment. BMJ Careers 2011; 21 April (http:// careers.bmj.com/careers/advice/view-article.html?id = 20002682).

15 Maidment R, Livingstone G, Katona M, Whitaker E, Katona C. Carry on shrinking: career intentions and attitudes to psychiatry of prospective medical students. Psychiatr Bull 2003; 27: 30-2

16 Maidment R, Livingstone G, Katona C, McParland M, Noble L. Change in attitudes to psychiatry and intention to pursue psychiatry as a career in newly qualified doctors: a follow up of two cohorts of medical students. Med Teach 2004; 26: 565-9.

17 Merton RK, Bloom S, Rogoff N. Studies in the sociology of medical education. J Med Educ 1956; 31: 552-65.

18 Pardes $\mathrm{H}$. Medical educational and recruitment in psychiatry. Am J Psychiatry 1982; 139: 1033-5.

19 Burra P, Kalin R, Leichner PWJJ, Handforth JR, Jarrett FJ, Amara IB. The ATP - a scale for measuring medical student's attitude to psychiatry. J Med Educ 1982; 16: 31-8.
20 Wilkinson DG, Greer S, Toone BK. Medical students attitude to psychiatry. Psychol Med 1983; 13: 185-92.

21 Brown TM, Addie K, Eagles JM. Recruitment into psychiatry: views of consultants in Scotland. Psychiatr Bull 2007; 31: 411-3.

22 Pailhez G, Bulbena A, Coll J, Salvador R, Balon R. Attitudes and views on psychiatry: a comparison between Spanish and US medical students. Acad Psychiatry 2005; 29: 82-91.

23 Whitecomb ME, Cohen JJ. The future of primary care medicine. $N$ Eng J Med 2004; 351: 710-2.

24 Creed F, Goldberg D. Students' attitudes towards psychiatry. Med Educ 1987; 21: 227-34.

25 Singh SP, Baxter $\mathrm{H}$, Standen P, Duggan C. Changing the attitudes of 'tomorrow's doctors' towards mental illness and psychiatry: a comparison of two teaching methods. Med Educ 1998; 2: 115-20.

26 Department of Health, Ireland. Medical Education in Ireland: A New Direction. Report of the Working Group on Undergraduate Medical Education and Training (the 'Fottrell Report'). The Department of Health, Ireland, 2006 (http://www.dohc.ie/publications/pdf/fottrell. pdf?direct =1).

27 Cameron P, Persad E. Recruitment into psychiatry: a study of the timing and process of choosing psychiatry as a career. Can J Psychiatry 1984; 29: $676-80$.

28 Nemetz P, Weiner H. Some factors in the choice of psychiatry as a career. Arch Gen Psychiatry 1965; 13: 299-303.

29 Gowans MC, Glazier L, Wright BJ, Brenneis FR, Scott IM. Choosing career in psychiatry: factors associated with a career interest in psychiatry among Canadian students on entry to medical school. Can J Psychiatry 2009; 54: 557-64.

30 Oxford University. Medical School Prospectus. Oxford University, no date (http://www.medsci.ox.ac.uk/study/medicine/prospectus/A100\%20 brochure\%202012.pdf).

31 Mowbray R, Davies B. Personality factors in choice of medical specialty. Br J Med Educ 1971; 5: 110-7.

32 Howe A, Ives G. Does community-based experience alter career preference? New evidence from a prospective longitudinal cohort study of undergraduate medical students. Med Educ 2001; 35: 391-7. 